\title{
An Analysis of Phonetic, Morphological and Syntactic Errors in English: A Case Study of Saudi BA Students at King Khalid University
}

\author{
Khalid Al-Badawi
}

\begin{abstract}
The objective of this study was to identify common phonetic, morphological and syntactic errors committed by native Arabic-speaking learners of English during speaking tasks using Corder's (1967) and Dulay's (1982) descriptive approach towards error analysis. The most common phonetic, morphological and syntactic errors, respectively, identified among a selected sample of 20 Saudi English were substitution of the consonants $/ \mathbf{f} /$ for $/ v /$ and $/ \mathbf{p} /$ for $/ \mathbf{b} /$ and the vowels $/ \mathrm{a} /$ for $/$

$J /, /$ / for $/ \mho /$ and $/ \varepsilon /$ for $/ I /$; failure to use the plural and third-person singular (-s/es), the comparative (-er), and the progressive (-ing); and lack of subject-verb agreement, erroneous use of prepositions, and erroneous addition and deletion of certain auxiliaries.
\end{abstract}

Index Terms-Applied linguistics, English as a foreign language, English as a second language, error analysis, morpheme, phoneme, segment, syntax.

\section{INTRODUCTION}

Error analysis is an applied linguistics approach used to identify areas of great difficulty for second language learners by applying a system of formal distinction to differentiate between the learner's first language (L1) and target language (L2; Corder, 1967; Dulay, 1982). Such analysis is based on the understanding that both intralingual and interlingual factors determine the type of errors. Whereas the former involves difficulties faced by the learner due to distinctive linguistic features of the L2 itself, the latter involves the direct interference of negative transfer of structures and other features from the L1 to the L2. As use of error analysis has led to discovery that learners' errors reflect a gap in their competence, order of acquisition and accuracy in order of learning, it has become an important instrument in first and second language learning research.

According to Odlin (1989), L1 syntactic, phonetic and morphological features exert powerful influences on production of L2 structures and pronunciation. Selinker (1992) clarified that transfer of L1 structure to L2 performance is negative and errors are inevitable when L1 and L2 structures differ but positive when the structures are similar. A particular challenge identified by Cook (1992) is that regardless of the teacher's efforts, L1 knowledge remains present in the minds of L2 learners, who connect it with L2 knowledge. He therefore warned not to treat the L2 in isolation from the L1. Among the distinctive errors

Manuscript received October 20, 2012; revised November 29, 2012

Khalid Al-Badawi is with King Khalid University (e-mail: sunrisekb@hotmail.com) committed by native Arabic speakers, El-Hibir and Althaha (1995) found that the most common was articulation of the segment $/ \mathrm{v} /$ as $/ \mathrm{f} /$, which, as $/ \mathrm{v} /$ is not present in the phonemic system of Arabic, they attributed to the interference of L1 on L2. In contrast, Khuwaileh and Shoumali (2000) found that most errors were related to tense due to lack of time sequence. Barros (2003) identified difficulty with the phoneme $/ \mathrm{y} /$ in the final position, which he attributed it to L1 interference; specifically, as $/ \mathfrak{y} /$ does not exist in Arabic, Arabic speakers replace it with $/ \mathrm{n} /$ or $/ \mathrm{m} /$, which do exist in Arabic, just as they substitute the voiced /b/ for the voiceless stop /p/, which also does not exist in Arabic. Explaining that Arabic vowels have a different place of articulation and syllable structure from those of English, Odisho (2005) asserted that vowel misarticulation by native Arabic speakers can be attributed to L1 interference on L2 when they attempt to pronounce a vowel that has no close counterpart in Arabic.

\section{Statement of the Problem And Study ObJective}

Saudi students of English as a Foreign Language at King Khalid University (KKU) commit certain phonetic, morphological and syntactic errors when using English in different environments. The objective of this study was to identify the most common errors committed by a selected sample of students and the factors responsible for these errors.

\section{RESEARCH QUESTIONS}

This study addressed the following research questions to explicate the phonetic, morphological and syntactic errors committed by a selected sample of Saudi students:

1) What types of phonetic errors are committed by learners?

2) What types of morphological errors are committed by learners?

3) What types of syntactic errors are committed by learners?

4) How does L1 interference lead to errors in L2 production?

\section{STUdY SAMPLE}

This study examined a selected sample of 20 students (age range 19 to 20 years) from among the approximately 500 students in the Department of English, King Khalid 
University, Saudi Arabia who met the met the criteria of (a) having completed one year of English courses; (b) being currently enrolled in level three courses, categorized as intermediate-level courses in the English Department; (c) having strong motivation to improve their language skills; (d) experiencing constant interaction with native English-speaking teachers of English; and (e) being sufficiently proficient in English to participate in a one-hour discourse meeting related to the research objectives.

\section{Methods of Data Collection}

A qualitative interview approach was used to collect the study data. Audio-recorded field interviews lasting approximately 10 minutes were conducted with each subject on the KKU campus and later reviewed for identification of common phonetic, morphological and syntactic errors.

\section{RESULTS}

\section{A. Phonetic Errors}

Regarding misarticulation of consonants, $60 \%$ of the sample substituted the voiced bilabial $/ \mathrm{b} /$ for the bilabial voiceless $/ \mathrm{p} /$ in the initial position and $45 \%$ substituted it in the medial position. When L2 speakers commit this error, the segment loses the articulation feature of [-voiceless] and gains the feature [+voiced], thereby maintaining the place of articulation. Large percentages also substituted the labiodental fricative /f/ for the voiced $/ \mathrm{v} /$ in the initial position $(40 \%)$ and in the medial position (60\%). When L2 speakers this error, the segment maintains the place of the articulation feature but loses the [+voiced] manner of articulation. These errors occur due to the absence of $/ \mathrm{p} /$ and $/ \mathrm{v} /$ in the Arabic phonological system, and thus reflect negative L1 interference. Regarding vowels, $40 \%$ of the sample substituted /ə/ for / /, 37.5\% substituted /ə/ for $/ \mathrm{J} /$, and $50 \%$ substituted $/ \varepsilon /$ for $/ \mathbf{I} /$. Moreover, 55\% substituted /I/ for the diphthong /ej/. In contrast to misarticulation of consonants, such misarticulation of vowels arises from lack of knowledge of the vowel system of English rather than L1 interference.

\section{B. Morphological Errors}

Large percentages of the sample failed to use the plural (-s/es) in certain noun phrases $(62.5 \%$ of the sample), erroneously retained the past tense (-ed) despite the use of the past indicators 'ago' and 'last' (37.5\%), failed to add the third-person singular ( $\mathrm{s} / \mathrm{es}$ ) to indicative verbs $(45 \%)$, and failed to use the marker (-er) when comparing two items $(60 \%)$. Regarding the use of the marker (-ing), $80 \%$ failed to use the marker in progressive constructions, $32.5 \%$ substituted the derivational morpheme (-ment) for the inflectional suffix (-ing) and $25 \%$ failed to add the inflectional suffix (-ing) to form a gerund. These types of errors are theoretically categorized using the surface structure taxonomy, particularly those concerning omission or addition due to lack of knowledge or developmental errors.

\section{Syntactic Errors}

Most syntactic errors committed by the sample can be attributed to a lack of L2 knowledge. Specifically, $42.5 \%$ of the sample violated subject-verb agreement in noun phrases due to lack of knowledge of the plural system of English nouns, $57.5 \%$ failed to use the adverbial 'because' due to lack of knowledge of cause-effect adverbial clauses, $50 \%$ failed to use the indefinite article (a/an) due to lack of awareness that each noun phrase must be preceded by a determiner, and $70 \%$ erroneously substituted the indefinite article (a/an) for the definite article (the). Large percentages also used certain prepositions incorrectly due the absence of certain adverbs of place in Arabic (57.5\%), failed to use the correct time sequence due to lack of awareness that all the verbs in a time sequence in a sentence must carry the same tense as that of the first verb $(50 \%)$, failed to use $(50 \%)$ or erroneously repeated $(27.5 \%)$ the auxiliary (be) due to the absence of this auxiliary in Arabic, failed to use the restrictive relative pronoun (who) after the noun phrase due to lack of awareness that each noun phrase that constitutes a clause in the embedded position must be followed by a relative pronoun $(40 \%)$ and added another noun phrase of the same category to the subject of a sentence (30\%). Based on these results, it appears that the students experience the greatest difficulty in using definite and indefinite articles and the least difficulty in using the auxiliary 'be'.

\section{CONCLUSION}

The results of the study confirm El-Hibir and Althaha's (1995) finding regarding the widespread substitution of /f/ for /v/ and for both El-Hibir and Althaha's and Barros's (2003) findings regarding that of $/ \mathrm{b} /$ for $/ \mathrm{p} /$ among native Arabic-speaking learners of English. Such misarticulation can be attributed to the absence of $/ \mathrm{v} /$ and $/ \mathrm{p} /$ in the Arabic phonological system, leading L2 learners to substitute Arabic equivalents for them that are imperfect in that they have a different manner of articulation. In contrast, L2 learners cannot substitute Arabic equivalents for English vowels that are absent from the Arabic phonological system because no such vowels are available, and must thus rely on their often-imperfect knowledge of English vowels. Regarding morphological errors, the results indicate that a failure to use or a tendency to misuse certain morphemes arises from lack of knowledge of English morphemes, whereas syntactic errors tend to arise from negative L1 interference on L2 structures. The findings of this study demonstrate the utility of employing error analysis in identifying phonetic, morphological and syntactic errors among L2 learners to gain understanding of their causes.

\section{REFERENCES}

[1] A. Barros, "Pronunciation difficulties in the consonant system experienced by Arabic speakers when learning English after the age of the puberty," West Virginia University, Morgantown, USA, 2003.

[2] F. Bataineh. "Jordanian undergraduate EFL students' errors in the use of the indefinite article," Asian EFL Journal, vol. 7, no. 1, pp. 56-67, 2005 .

[3] V. Cook, "Evidence for multi-competence Language learning," vol. 42, no. 4, pp. 557-591, 1992.

[4] P. Corder, "The significance of learners' errors," International Review of Applied Linguistics, vol. 5, pp. 161-170, 1967. 
[5] H Dulay, M. Burt, and S. Krashen, Language two, Oxford: Oxford University press, 1982.

[6] I. E. Hibir and F. A. Taha, "Orthographic errors of Saudi students learning English," Language Learning Journal, vol. 5, no. 1, pp. 85 87, 1992.

[7] A. Khuwaileh and A. Shoumali, Language Culture and Cirriculaum, vol. 1, pp. 174-183.

[8] R. Lado, The construction and use of foreign language test, U.K. Longman, 1957.

[9] L. Mukkatash, The problem of difficulty in foreign learning, Papers from the First Conference on the Problems of Teaching English Language and Literature at Arab Universities, Amman- Jordan: University of Jordan

[10] E. Odisho, Techniques of teaching comparative pronunciation in Arabic and English, NJ: Gorgias Press, 2005.

[11] T. Odlin, Language transfer: Cross-linguistic influence in language learning, 1989.
[12] L. Selinker, Rediscovering interlanguage, London: Longman, 1992.

[13] J. Yule, The study of language. Cambridge, Cambridge University Press, 2006.

[14] M. Zughoul and L. Taminian, "The Linguistics attitude of Arab university students, factorial structure and interviewing variables," The International Journal of Sociology of Language, vol. 50, pp. 155-179, 1984.

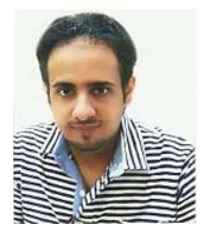

Khalid Al-Badawi is a Lecturer of Applied Linguistic in College of Language \& Translation, King Khalid University, Abha, and Kingdom of Saudi Arabia. 